〈단보〉

\author{
유전자 변이 대두와 옥수수 함유 사료가 \\ 참전복(Haliotis discus hannai) 치패의 성장과 체조성에 미치는 영향 \\ 이상민 ${ }^{*}$ 남윤권 ${ }^{1}$ 김동수 ${ }^{1}$ \\ 강릉원주대학교 해양생물공학과, ${ }^{1}$ 부경대학교 해양바이오신소재학과
}

\title{
Influences of Dietary Inclusion of Genetically Modified Soybean or Corn on the Growth Performance and Body Composition of Juvenile Abalone Haliotis discus hannai
}

\author{
Sang-Min Lee* ${ }^{*}$ Yoon-Kwon Nam ${ }^{1}$ and Dong-Soo Kim ${ }^{1}$ \\ Department of Marine Bioscience and Technology, Gangneung-Wonju National University, Gangneung 210-702, Korea \\ ${ }^{1}$ Department of Marine Bios-Materials and Aquaculture, Pukyong National University, Busan 608-737, Korea
}

Two feeding experiments were conducted to investigate the effects of dietary inclusion of genetically modified (GM) soybean and corn on the growth performance, feed utilization and body composition of juvenile abalone Haliotis discus hannai. Four isonitrogenous (31\% crude protein) and isolipidic (6\% crude lipid) diets (designated as nGM-soya, GM-soya, nGM-corn and GM-corn) were formulated to contain 20\% non-GM (nGM) and GM soya and corn. Fifty juvenile abalone (initial body weight, $2.0 \mathrm{~g}$ ) were distributed in each $50 \mathrm{~L}$ tank in a flow-through system. Each experimental diet was fed to duplicate groups of abalone to satiation once a day for 10 weeks. No effects of GM feedstuffs on survival were observed. Dietary inclusion of GM feedstuffs did not affect either growth performance or feed utilization of abalone. Body composition was not altered by the inclusion of GM feedstuffs. These results indicate that dietary inclusion of GM soybean and corn could have no effect on the growth performance and body composition of juvenile abalone. Further studies to investigate the effects of GM feedstuffs on transgenic fragment residues in ambient environments and in animals are necessary for the safe use of such ingredients in aquaculture.

Key words: Abalone, Haliotis discus hannai, GM-soybean, GM-corn, Growth, Body composition

\section{서 론}

전복은 세계계적으로 100 여종 이상이 분포하고 있으며, 우리 나라에는 말전복(Haliotis giganta), 둥근전복(H. discus), 시볼 트 전복(H. sieboldii), 오분자기(H. diversicolor superfexta) 및 참전복(H. discus hannai) 등이 서식하고 있다. 이 중 참전복은 우리나라의 주요한 양식 대상종으로 최근에 완도를 비롯한 남해 안에서 양식에 의한 생산량이 계속 증대되고 있는 추세이다. 이 처럼 전복양식에 관한 관심이 증가함에 따라 기존의 가두리 양 식을 비롯하여 육상수조에서도 고밀도로 전복을 양성하는 곳이 증가되는 등 양식방법이 다양해지고 있다(Jee et al., 1988; Kim et al., 1998a, b; Jeong et al., 1994). 그러나 전복 양식을 위해 양 어가들은 육성용 먹이로 미역과 다시마와 같은 천연 먹이에 의 존하고 있는데, 이러한 해조류는 지역에 따라 공급이 불안정할

*Corresponding author: smlee@gwnu.ac.kr
수 있을 뿐 아니라 가격의 변동이 심하고, 성장 또한 배합사료로 사육하는 것보다 낮은 것으로 보고되어 있다(Lee et al., 1997; Viana et al., 1993).

지금까지 참전복용 경제적인 배합사료를 개발하기 위해서 많은 연구(Lee et al., 1998a,b,c; Lee and Park, 1998)가 수행되 었다. 사료의 단백질원에 대한 평가는 배합사료의 품질을 향상 시키고, 사료단가를 절감시킬 수 있는 중요한 연구이다. Lee et al. (1998)은 어분, 대두박, 면실박 또는 미역분말이 참전복 배합 사료에 적합한 단백질원이라고 발표하였으며, 이들 원료를 적 절히 배합하여 사용하면 참전복 사료의 단가를 절감시킬 수 있 을 것으로 기대하였다. 이러한 연구 결과를 바탕으로 Lee(1998) 는 어분과 대두박을 주 단백질원으로 사용한 경제적인 배합비 를 제시하였다. 이중에서 대두박은 단백질 함량과 필수 아미노 산이 풍부하기 때문에 어류 사료의 단백질원인 어분을 대체할 수 있는 식물성 단백질원으로서 가장 많이 연구되고 있다(NRC, 1993). 
Table 1 . Proximate composition (\% dry matter) of dietary ingredients

\begin{tabular}{lcccc}
\hline & \multicolumn{4}{c}{ Ingredients } \\
\cline { 2 - 5 } & nGM soya & GM soya & nGM corn & GM corn \\
\hline Crude protein & 37.5 & 37.0 & 11.1 & 7.4 \\
Crude lipid & 19.7 & 20.5 & 5.4 & 3.6 \\
Ash & 5.2 & 4.9 & 1.7 & 1.1 \\
Carbohydrate $^{1}$ & 37.6 & 37.6 & 81.8 & 87.9 \\
\hline
\end{tabular}

${ }^{1}$ Calculated $=100-($ crude protein + crude lipid + ash $)$.

Table 2. Ingredients composition of the experimental diets

\begin{tabular}{|c|c|c|c|c|}
\hline & \multicolumn{4}{|c|}{ Diets } \\
\hline & nGM-soya & GM-soya & nGM-corn & GM-corn \\
\hline \multicolumn{5}{|c|}{ Ingredients (\% of air-dried) } \\
\hline Casein & 20.0 & 20.0 & 20.0 & 30.0 \\
\hline nGM soya & 30.0 & & & \\
\hline GM soya & & 30.0 & & \\
\hline nGM corn & & & 30.0 & \\
\hline GM corn & & & & 30.0 \\
\hline Dextrin & 30.0 & 30.0 & 16.4 & 16.4 \\
\hline Squid liver oil & 1.0 & 1.0 & 4.6 & 4.6 \\
\hline Vitamin premix ${ }^{1}$ & 1.5 & 1.5 & 1.5 & 1.5 \\
\hline Mineral premix ${ }^{2}$ & 2.0 & 2.0 & 2.0 & 2.0 \\
\hline Na-alginate & 15.0 & 15.0 & 15.0 & 15.0 \\
\hline Choline salt (50\%) & 0.5 & 0.5 & 0.5 & 0.5 \\
\hline \multicolumn{5}{|c|}{ Proximate analysis (\% of dry matter basis) } \\
\hline Crude protein & 30.6 & 32.1 & 32.4 & 31.0 \\
\hline Crude lipid & 6.1 & 6.2 & 6.1 & 6.1 \\
\hline Ash & 4.5 & 4.6 & 4.6 & 4.7 \\
\hline
\end{tabular}

${ }^{1}$ Vitamin mix contained the following amount which were diluted in cellulose (g/kg mix): L-ascorbic acid, 200; DL- $\alpha$ -tocopheryl acetate, 20; thiamin hydrochloride, 5; riboflavin, 8; pyridoxine hydrochloride, 2; nicin, 40; Ca-D-pantothenate, 12; myo-inositol, 200; D-biotin, 0.4; folic acid (98\%), 1.5; p-aminobenjoic acid, 20; menadione, 4; retinyl acetate, 1.5; cholecalciferol, 0.003; cyanocobalamin, 0.003 .

${ }^{2}$ Mineral mix contained the following ingredients (g/ $\left.\mathrm{kg} \mathrm{mix}\right)$ : $\mathrm{NaCl}, 10, \mathrm{MgSO}_{4} \cdot 7 \mathrm{H}_{2} \mathrm{O}, 150 ; \mathrm{NaH}_{2} \mathrm{PO}_{4} .2 \mathrm{H}_{2} \mathrm{O}, 250 ; \mathrm{KH}_{2} \mathrm{PO}_{4}$, 320; $\mathrm{CaH}_{4}\left(\mathrm{PO}_{4}\right)_{2} . \mathrm{H}_{2} \mathrm{O}, 200 ;$ Ferric citrate, $25 ; \mathrm{ZnSO}_{4} \cdot 7 \mathrm{H}_{2} \mathrm{O}$, 4; Ca-lactate, 38.5; $\mathrm{CuCl}, 0.3 ; \mathrm{AlCl}_{3} .6 \mathrm{H}_{2} \mathrm{O}, 0.15 ; \mathrm{KIO}_{3}, 0.03$; $\mathrm{Na}_{2} \mathrm{Se}_{2} \mathrm{O}_{3}, 0.01 ; \mathrm{MnSO}_{4} \cdot \mathrm{H}_{2} \mathrm{O}, 2 ; \mathrm{CoCl}_{2} \cdot 6 \mathrm{H}_{2} \mathrm{O}, 0.1$.

미국이나 캐나다 등의 국가들은 질병 또는 환경 저항성 유전 자변이 $(\mathrm{GM})$ 대두나 옥수수를 생산하여 식품이나 사료용으로 공급하고 있으며, 일부는 국내에서도 유통되고 있는 실정이다. 최근에 GM 대두, 옥수수, 면실 등의 농산물이 국내에 수입되어 식용유나 전분제조에 이용되고 부산물은 사료원료로 사용되고 있다. 유전자 변형 원료의 사용은 잠재적으로 위험성을 가질 수
Table 3. Growth performances of juvenile abalone $H$. discus hannai fed the experimental diets for 10 weeks ${ }^{1}$

\begin{tabular}{lcccc}
\hline & \multicolumn{4}{c}{ Diets } \\
\cline { 2 - 5 } & nGM-soya & GM-soya & nGM-corn & GM-corn \\
\hline Initial mean weight $(\mathrm{g})$ & $2.0 \pm 0.1$ & $2.0 \pm 0.1$ & $2.0 \pm 0.1$ & $1.9 \pm 0.1$ \\
Survival (\%) & $99 \pm 1.0$ & $98 \pm 2.0$ & $96 \pm 2.8$ & $98 \pm 0.1$ \\
Weight gain (\%) & $34.2 \pm 0.1$ & $42.2 \pm 3.7$ & $65.1 \pm 8.5$ & $62.2 \pm 5.1$ \\
Shell length (cm) & $3.0 \pm 0.1$ & $3.0 \pm 0.1$ & $3.1 \pm 0.1$ & $3.1 \pm 0.1$ \\
Shell width (cm) & $2.0 \pm 0.1$ & $2.0 \pm 0.1$ & $2.1 \pm 0.1$ & $2.1 \pm 0.1$ \\
Soft body weight/ & $0.63 \pm 0.1$ & $0.59 \pm 0.1$ & $0.6 \pm 0.1$ & $0.7 \pm 0.1$ \\
body weight & & & & \\
\hline
\end{tabular}

${ }^{1}$ Values presented are mean \pm SE of replications.

${ }^{2}$ (Final weight-initial weight) $\times 100 /$ initial weight.

Table 4. Chemical composition (\%) of the soft body of juvenile abalone $H$. discus hannai fed the experimental diets for 10 weeks $^{1}$

\begin{tabular}{lcccc}
\hline & \multicolumn{4}{c}{ Diets } \\
\cline { 2 - 5 } & nGM-soya & GM-soya & nGM-corn & GM-corn \\
\hline Moisture & $76.8 \pm 0.5$ & $76.6 \pm 0.2$ & $75.9 \pm 0.7$ & $77.5 \pm 0.7$ \\
Crude protein & $17.9 \pm 0.4$ & $17.1 \pm 0.1$ & $15.7 \pm 0.6$ & $15.2 \pm 0.3$ \\
Crude lipid & $0.6 \pm 0.2$ & $0.7 \pm 0.1$ & $0.9 \pm 0.1$ & $0.7 \pm 0.2$ \\
Ash & $2.6 \pm 0.1$ & $2.4 \pm 0.1$ & $2.4 \pm 0.1$ & $2.4 \pm 0.1$ \\
\hline
\end{tabular}

${ }^{1}$ Values presented are mean $\pm \mathrm{SE}$ of two replications.

있는데, 본질적 속성이나 형질 및 목적을 변경 시킬 수 있다고 보고되고 있다(EFSA, 2008). 특히, 임의적인 트랜스유전자가 숙주 유전체내로 들어가면 유전자 발현에 혼란을 일으킬 수 있 으며, 영양소의 구성 물질이나 특성을 변형 시킬 수 있다(Cellini et al., 2004). 유전자 변형 식물성원료로 어류의 사육실험을 수 행한 몇 가지 연구가 보고되어 있다. 돔을 대상으로 유전자 변 형 루핀을 첨가하여 메티오닌 증가를 평가한 연구(Glencross et al., 2003)와 대서양 연어 사료에 비티 옥수수(Bt-maize)를 첨가 한 실험(Sanden et al., 2005, Hemre et al., 2007; Sissener et al., 2009), 그리고 국내에서도 유전자 변형 대두와 옥수수를 사료에 첨가하여 넙치와 조피볼락의 성장 및 체조성에 대한 영향을 평 가한 실험(Pham et al., 2010)이 보고되어 있다. 본 연구에서는 유전자 변형 대두박과 옥수수가 전복 육성용 배합사료의 원료로 사용되었을 때 전복의 성장 및 체조성에 미치는 영향을 조사하 여 사료제조에 기초적인 정보를 제공하기 위해 수행되었다.

\section{재료 및 방법}

\section{실험사료}

실험에 사용된 일반 대두박(nGM-soya), 유전자 변이 대두 박(GM-soya), 일반 옥수수(nGM-corn)와 유전자 변이 옥수수 (GM-corn)는 Pham et al. (2010)이 사용한 것과 동일한 것이다. 
원료의 일반성분은 Table 1에, 사료조성 및 영양성분은 Table 2 에 나타내었다. 카제인을 주 단백질원으로 한 실험사료에 대두 (대두: nGM-soya, 유전자 변이 대두: GM-soya)를 분쇄하여 각 각 $30 \%$ 씩 첨가하였다. 실험사료의 탄수화물원으로 덱스트린 을, 지질원으로 오징어간유를, 점착제로 알긴산나트륨을 각각 첨가하였다. 옥수수(nGM-corn)와 유전자 변이 옥수수(GMcorn)의 첨가도 대두박 실험 사료와 유사하게 설계하였다. 실험 사료는 원료를 잘 혼합한 후 사료원료 $1 \mathrm{~kg}$ 당 증류수 $1 \mathrm{~L}$ 를 첨 가하여 혼합반죽 후 압착하여 $5 \%$ 염화칼슘 수용액에 1 분간 침 지 후, 가로 $1 \mathrm{~cm}$, 세로 $1 \mathrm{~cm}$ 로 절단하여 그늘진 곳에서 48 시간 건조하였다. 성형된 실험사료는 냉장고에 보관하면서 전복치패 에 공급하였다.

\section{실험어 및 사육관리}

강원도 수산 자원연구소에서 전복 치패를 분양 받아 강릉원 주대학교 해양생물연구교육센터로 수송한 후 실험어로 사용하 였다. 2주간 예비 사육한 후, 평균체중 $2.0 \mathrm{~g}$ 의 전복을 선별하여 2 반복으로 12 개의 사각수조 $(50 \mathrm{~L})$ 에 수용하여 10 주간 사육실험 하였다. 실험사료는 전복 체중의 3-5\%씩 2일 1회 오후(17:00) 에 공급하였다. 각 수조마다 약하게 폭기시켜 산소를 공급하였 고, shelter를 넣어 은신처를 만들어 주었다. 사육기간 동안 사육 수조의 수온과 용존산소(DO)는 DO meter(YSI-550A, U.S.)를 사용하여 측정하였고, $\mathrm{pH}$ 는 $\mathrm{pH}$ meter(Mettler-Toled $\mathrm{pH}$ meter $\mathrm{SG} 2$, Switzerland)를 사용하여 측정하였다. 사육수의 평균 수온 은 $13.5 \pm 2.9^{\circ} \mathrm{C}, \mathrm{pH}$ 는 $7.3 \pm 0.5$ 그리고 $\mathrm{DO}$ 는 $7.6 \pm 0.78 \mathrm{ppm}$ 이 었다.

\section{시료채취 및 성분분석}

실험종료 시에 각 수조에 수용된 전복 치패들의 총무게를 측 정하고, 생존한 전복을 모두 샘플로 취하여 냉동보관 $\left(-24^{\circ} \mathrm{C}\right)$ 하 였다. 전복 치패의 각장과 각폭을 측정하고, 가식부의 무게를 측정 후 성분 분석에 사용되었다. 실험사료와 전어체의 일반성 분은 $\mathrm{AOAC}(1995)$ 의 방법에 따라 조단백질 $(\mathrm{N} \times 6.25)$ 은 Auto Kjeldahl 장치를 사용하여 분석하였고, 조지방은 ether 추출법을 사용하여 분석하였다. 수분은 $105^{\circ} \mathrm{C}$ dry oven에서 6시간 동안 건조 후 측정하였고, 회분은 $600{ }^{\circ} \mathrm{C}$ 회화로에서 4 시간 동안 태운 후 측정하였다.

\section{통계처리}

결과의 통계처리는 SPSS(version 17.0) program을 사용하여 t-test로 평균간의 유의성을 검정하였다.

\section{결과 및 고찰}

평균체중 $2.0 \mathrm{~g}$ 의 전복치패를 대두(nGM-soya, GM-soya) 및 옥수수(nGM-corn, GM-corn)가 함유된 실험사료로 10주간 사육실험한 결과를 Table 3 에 나타내었다. 생존율, 증중율, 각
장, 각폭 및 가식부 중량비는 실험구간에 유의한 차이가 없었 다 $(P>0.05)$. 그리고 $\mathrm{nGM-corn}$ 과 $\mathrm{GM}$-corn을 첨가한 실험사 료로 전복치패를 10 주간 사육실험한 결과, 생존율, 증중율, 각 장, 각폭 및 가식부 중량비는 실험구간에 유의한 차이가 없었다 $(P>0.05)$

사육실험 종료 후, 대두(nGM-soya, GM-soya) 및 옥수수 (nGM-corn, GM-corn) 첨가 사료를 공급한 전복치패 가식부 의 일반성분 분석결과를 Table 4에 나타내었다. 수분, 조단백질, 조지질 및 회분 함량은 모든 실험구간에 유의한 차이가 없었다 $(P>0.05)$. Table 4에 표시한 바와 같이 nGM-corn과 GM-corn 첨가사료를 10 주간 공급한 후의 가식부 수분, 조단백질, 조지질 및 회분 함량 모두 nGM-corn과 GM-corn 실험구간에 유의한 차이가 없었다 $(P>0.05)$.

이러한 성장결과들은 $\mathrm{GM}$ 대두나 옥수수를 사료에 첨가하여 도 전복의 성장이나 체성분에 영향을 미치지 않음을 암시하고 있다. GM 대두나 옥수수가 함유된 사료가 연어의 성장, 사료효 율, 건강, 유전자 발현을 조사한 최근의 연구에서(Sanden et al., 2004; Hemre et al., 2005; 2007; Sanden et al., 2006; Frøystad et al., 2007; Sissener et al., 2009), Hemre et al. (2005)은 13\% 의 $\mathrm{GM}$ 대두가 함유된 사료를 연어에 공급하여도 성장, 사료효 율, 체성분, 면역 및 혈액성상 등이 non-GM을 공급한 대조구와 차이가 없었다고 보고하고 있어, 본 연구와 유사한 결과를 보였 다. 또한, Glencross et al. (2003)은 Pagrus auratus 사료에 GMlupin을 첨가하여도 성장이나 사료이용효율에 영향이 없었다고 보고하였다. 반면에 GM 옥수수가 함유된 사료를 섭취한 연어 의 경우, 사료섭취율 및 성장이 상대적으로 감소하였다는 보고 도 있어 차이를 보였다(Hemre et al., 2007). 이러한 차이는 원료 나 대상 어종의 차이에 의한 것으로 판단된다.

본 연구에서 대두가 함유된 실험사료를 섭취한 전복의 성 장이 옥수수가 함유된 사료섭취구보다 낮은 경향을 보였다. 이 는 대두에 함유된 trypsin inhibitor나 phytic acid와 같은 항영 양인자의 함량이 높았기 때문으로 추정된다(Lee et al., 1991; Bjerkeng et al., 1997; Francis et al., 2001; Lim et al., 2004). Trypsin inhibitor와 같은 항영양인자은 기름추출과정에서 처리 되는 고압이나 열에 의해 대부분이 파괴되어 사료원료로 사용될 때는 그 함량이 매우 낮은 것으로 알려져 있다. 하지만 본 연구 에서 사용된 대두는 기름을 추출하지 않은 full-fat 대두를 분쇄 기로 분쇄한 것으로 항영양인자가 제거되지 못한 상태였기 때문 에 대두가 함유된 사료 섭취구의 전복 성장이 옥수수가 함유된 사료를 섭취한 전복에 비해 상대적으로 낮았을 것으로 판단된 다.

결론적으로 보면, 본 연구에서 사용한 $\mathrm{GM}$ 대두나 옥수수를 참전복 양성용 배합사료에 사용하였을 때 성장 및 체성분에 영 향을 미치지 않은 것으로 나타났다. 또한, 열처리 등의 공정을 거치지 않은 full-fat 대두의 사용은 항영양인자의 함유로 전복 의 성장을 감소시킬 수 있기 때문에 이를 고려하여야 할 것이다. 본 연구에서는 $\mathrm{GM}$ 원료가 배합사료에 첨가되었을 때, 원료의 
영양소 소화율, 생체 소화기관의 조직과 소화효소활성, 호르몬 분비, 유전자발현, 환경 노출에 의한 생태환경 변화 등 광범위한 항목들이 조사되지 못한 한계가 있었다. 금후 양어용 배합사료 에 $\mathrm{GM}$ 곡류 첨가시 이러한 면들을 고려하여 지속적인 연구가 수행되어 $\mathrm{GM}$ 곡류의 수입 및 사용 등에 참고가 될 유용한 정보 들을 축적하고, $\mathrm{GM}$ 곡류 사용에 따른 지속적인 모니터링이 수 행되어야 할 것이다.

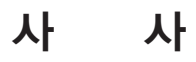

본 연구는 국토해양부 해양환경복원기술개발사업(과제번호 20088033-1)의 지원에 의해 수행되었습니다.

\section{참고문헌}

AOAC (Association of Official Analytical Chemists ). 1995. Official methods of analysis of Official Analytical Chemists International. 16th ed. Association of Official Analytical Chemists, Arlington, VA, U.S.A.

Bjerkeng B, Refstie S, Fjalestad KT, Storebakken T, Rodbotten M and Roem AJ. 1997. Quality parameters of the flesh of Atlantic salmon (Salmo salar) as affected by dietary fat content and full-fat soybean meal as a partial substitute for fish meal in the diet. Aquaculture 157, 297-309.

Cellini F, Chesson A, Colquhoun I, Constable A, Davies HV, Engel KH, Gatehouse AMR, Karenlampi S, Kok EJ, Leguay JJ. 2004. Unintended effects and their detection in genetically modified crops. Food Chem Toxicol 42, 10891125.

EFSA. 2008. Report of the EFSA GMO panel working group on animal feeding trials: safety and nutritional assessment of GM plants and derived food and feed: the role of animal feeding trials. Food Chem Tocicol 46, 1-70.

Frøystad MK, Lilleeng E, Bakke-Mckellep AM, Vekterud K, Hemre GI and Krogdahl K. 2007. Gene expression in distal intestine of Atlantic salmon (Salmo salar L.) fed genetically modified soybean meal. Aquacult Nutr 13, 1-11.

Francis G, Makkar HPS and Becker K. 2001. Antinutritional factors present in plant-derived alternate fish feed ingredients and the effects in fish. Aquaculture 199, 197227.

Glencross B, Curnow J, Hawkins W, Kissil GWN and Peterson D. 2003. Evaluation of the feed value of a transgenic strain of the narrow-lead lupin (Lupinus angustifolius) in the diet of the marine fish, Pagrus auratus. Aquacult Nutr 9, 197-206.

Hemre GI, Sanden M, Bakke-McKellep AM, Sagstad A and Krogdahl A.2005. Growth, feed utilization and health of
Atlantic salmon Salmo salar L. fed genetically modified compared to non-modified commercial hybrid soybeans. Aquacult Nutr 11, 157-167.

Hemre GI, Sanden M, Bakke-Mckellep AM, Danieli A, Acierno R, Maffia M, Froystad M, Krogdahl A and Sanden M. 2007. Nutritional, physiological and histological responses in Atlantic salmon, Salmo salar L. fed diets with genetically modified maize. Aquacult Nutr 13, 186-199.

Jee YJ, Yoo SK, Rho S and Kim SH. 1988. The stocking density and growth of young abalone Haliotis discus hannai Ino cultured in the hanging net cage. Bull Nat Fish Res Dev Agency 42, 59-69.

Jeong SC, Jee YJ and Son PW. 1994. Indoor tank culture of the abalone Haliotis discus hannai II. Effects of diets on growth of young abalone. J Aquacult 7, 77-87.

Kim BH, Lee SM, Go CS, Kim JW and Myeong JI. 1998a. Optimum stocking density of juvenile abalone (Haliotis discus hannai) fed formulated diet or macroalgae (Undaria). J Korean Fish Soc 31, 869-874.

Kim JW, Lee SM, Han SJ, Kim BH and Park SR. 1998b. Effects of experimental diet, commercial diets and algae (Undaria) on growth and body composition among juvenile abalones (Haliotis discus, Haliotis sieboldii and Haliotis discus hannai). J Aquacult 11, 505-512.

Lee SM, Kang YJ and Lee JY. 1991. The effects of soybean meal as a partial replacement for white fish meal in diet for yellowtail (Seriola quinqueradiata). Bull Nat Fish Res Rev Dev Agen 45, 247-257.

Lee SM, Lee GA, Jeon IG and Yoo SK. 1997. Effects of experimental formulated diets, commercial diet and natural diet on growth and body composition of abalone (Haliotis discus hannai). J Aquacult 10, 417-424.

Lee SM and Park HG. 1998. Evaluation of dietary lipid sources for juvenile abalone (Haliotis discus hannai). J Aquacult 11, 381-390.

Lee SM, Yun SJ, Min KS and Yoo SK. 1998a. Evaluation of dietary carbohydrate sources for juvenile abalone (Haliotis discus hannai). J Aquacult 11, 133-140.

Lee SM, Yun SY and Hur SB. 1998b. Evaluation of dietary protein sources for abalone (Haliotis discus hannai). J Aquacult 11, 19-29.

Lee SM, Lim YS, Moon YB, Yoo SK and Rho S. 1998c. Effects of supplemental macroalgae and spirulina in the diets on growth performance in juvenile abalone (Haliotis discus hannai). J Aquacult 11, 31-38.

Lee SM. 1998. Evaluation of economical feed formulations for abalone (Haliotis discus hannai). J Aquacult 11, 159-166.

Lim SR, Choi SM, Wang XJ, Kim KW, Shin IS, Min TS and Bai SC. 2004. Effects of dehulled soybean meal as a fish 
meal replacer in diets for fingerling and growing Korean rockfish Sebastes schlegeli. Aquaculture 231, 457-468.

NRC (Nutrient Requirements of Fish). 1993. National Academic Press. Washington, DC., U.S.A., 50-51.

Pham, MA, Nam YK, Kim SH, Kim DS, Cho SH, Kim BS and Lee SM. 2010. Preliminary studies on the effects of dietary genetically modified soya and corn on growth performance and body composition of juvenile olive flounder (Paralichthys olivaceus) and rockfish (Sebastes schlegeli). Fish Aqua Sci 13, 63-70.

Sanden M, Bruce IJ, Rahman MA and Hemre GI. 2004. The fate of transgenic sequences present in genetically modified plant products in fish feed, investigating the survival of GM soybean DNA fragments during feeding trials in Atlantic salmon, Salmo salar L. Aquaculture 237, 391-405.

Sanden M, Bernssen MHG, Krogdahl Å, Hemre GI and Bakke-Mckellep AM. 2005. An examination of the intestinal tract of Atlantic salmon Salmo salar L. parr fed different varieties of soy and maize. J Fish Dis 28, 317330.
Sanden M, Krogdahl Å, Bakke-McKellep AM, Buddington PK and Hemre GI. 2006. Growth performance and organ development in Atlantic salmon, Salmo salar L. parr fed genetically modified (GM) soybean and maize. Aquacult Nutr 12, 1-14.

Sissener NH, Sanden M, Bakke AM, Krogdahl A and Hemre GI. 2009. A long term trial with Atlantic salmon (Salmon salar L.) fed genetically modified soy; focusing general health and performance before, during and after the parrsmolt transformation. Aquaculture 294, 108-117.

Viana MT, Lopez LM and Sals A. 1993. Diet development for juvenile abalone Haliotis fulgens. Evaluation of two artificial diets and macroalgae. Aquaculture 117, 149-156.

$\begin{array}{lll}\text { 2011년 } & \text { 5월 } & \text { 30일 접수 } \\ \text { 2011년 } & \text { 9월 } & \text { 15일 수정 } \\ \text { 2011년 } & \text { 9월 } & \text { 30일 수리 }\end{array}$

